\title{
Synovial Chondromatosis of Distal Radioulna Joint with Features of Lytic Lesion in a 29 years Male: A Case Report and Review of Literature
}

\author{
Kumar $\mathrm{N}^{*}$, Mukhopadhaya $\mathrm{J}$ and Anand $\mathrm{O}$
}

Department of Orthopaedics, PARAS HMRI, Patna, Bihar, India

\begin{abstract}
Background: Synovial chondromatosis is a rare, benign condition characterized by proliferation of synovial lining and metaplasia. The disease is usually mono articular and commonly involves knee joint, but it can also occur in shoulder, elbow, hip, ankle and wrist joints. A review of the literature produced 30 case reports of synovial chondromatosis of the wrist with only five cases showing recurrence $(5 / 30,17 \%)$. Because of its low prevalence and nonspecific symptoms, it can present diagnostic difficulties and lead to a delay in treatment.

Case: We report a 6 month follow up case of a 29 year old right hand dominant male who presented with complaint of pain and swelling in right wrist joints of four months duration. Plain X-ray revealed lytic lesion at distal end of right ulna with multiple radio opaque deposits. MRI and FNAC were in favour of Synovial chondromatosis. Patient underwent synovectomy and excision of calcific lesion through a dorsoulnar approach and a separate incision over radial styloid under general anaesthesia. Histopathology confirmed the diagnosis of Synovial chondromatosis. Patient had no recurrence till last follow up (6 Month).
\end{abstract}

Conclusion: Synovial chondromatosis of wrist joint is extremely rare. A close coordination between the clinician, radiologist and pathologist is essential for accurate diagnosis and management.

Keywords: Synovial chondromatosis, Wrist joint; loose bodies

\section{Introduction}

Synovial chondromatosis is a rare, benign, chronic, and progressive metaplasia associated with the formation of cartilage in the synovial membranes of joints, tendon sheath of bursae, of unknown aetiology [1]. When metaplastic foci become detached, loose bodies are produced. Synovial chondromatosis often affects the knee, hip or elbow, but rarely the hand ( $2 \%$ of cases). When the loose bodies undergo secondary ossification, the condition is called Synovial osteochondromatosis $[2,3]$. Tenosynovial chondromatosis has many similarities to synovial chondromatosis and probably represents an extra-articular counterpart of the same disease process [4]. Disease is usually monoarticular and the most common joint affected is the knee, but it can occur in hip, elbow, shoulder, ankle and wrist joint in the decreasing order of frequency [5]. Bilateral involvement is extremely rare. Documented case reports of bilateral presentation are usually seen in ankle joints, temperomandibular joints and rarely knee joints [6-8]. Careful clinical history, a thorough physical examination aided by radiology and histopathology leads to correct diagnosis and guides in planning management. We describe a case of Synovial chondromatosis of wrist joint with brief review of literature. A review of the literature produced 24 case reports of synovial chondromatosis of the wrist with only three cases showing recurrence.

\section{Case Report}

A 29 year old right hand dominant male presented with gradual pain and swelling in right wrist joints of four months duration. He was otherwise healthy with no medical history fever, night sweats, weight loss, any other joint swelling, no previous surgeries, and no prior injuries to his right hand or wrist.

Local examination revealed a solitary $2 \times 2 \mathrm{~cm}$ swelling over the dorsum of distal ulna, there was no local rise of temperature, it was immobile and fixed to underlying structures and there was mild tenderness. There was full range of movement and his grip strength was normal and there was no involvement of ulnar nerve. There was no epitrochlear or axillary lymphadenopathy.
The active range of motion of the right wrist included $50^{\circ}$ extension, $50^{\circ}$ flexion, $5^{\circ}$ ulnar deviation, and $20^{\circ}$ radial deviation. The active range of motion of the normal left wrist included $70^{\circ}$ extension, $80^{\circ}$ flexion, $20^{\circ}$ ulnar deviation and $30^{\circ}$ radial deviation. The patient complained of pain especially at the pisiform of one of the insertion sites of the FCU in resistive motion during ulnar deviation, wrist flexion and in passive motion during wrist extension, and radial deviation. In addition, he had an aching pain around the distal radioulnar joint in active wrist flexion and ulnar deviation.

Plain X-ray revealed lytic lesion (apple core appearance) at distal end of right ulna with multiple radio opaque deposits (Figure 1; Arrow Marked). An MRI showed mass located in the right interosseous membrane that encroached the distal radioulnar joint and the volar carpal joint The mass did not appear to invade the adjacent muscle compartments, tendons, or neurovascular bundles. The mass did not enhance on T1 sequence but had high signal intensity on proton density sequence and demonstrated irregular peripheral and nodular enhancement. MRI of right wrist showed possibility of synovial osteochondromatosis.

USG guided Fine needle aspiration from lytic lesion at distal end of right ulna showed FNA smears are sparsely cellular and are dominated by presence of cartilaginous matrix material. Few groups of chondrocytes are seen clustered together with large

*Corresponding author: Nishikant Kumar, Department of Orthopaedics, PARAS HMRI, Patna, Bihar, India, Tel: 9102303511; E-mail: knishikant@ymail.com

Received November 28, 2015; Accepted January 02, 2016; Published January 09, 2016

Citation: Kumar N, Mukhopadhaya J, Anand O (2016) Synovial Chondromatosis of Distal Radioulna Joint with Features of Lytic Lesion in a 29 years Male: A Case Report and Review of Literature. J Sports Med Doping Stud 6: 174 doi:10.4172/2161-0673.1000174

Copyright: ( 2016 Kumar N et al. This is an open-access article distributed under the terms of the Creative Commons Attribution License, which permits unrestricted use, distribution, and reproduction in any medium, provided the original author and source are credited. 


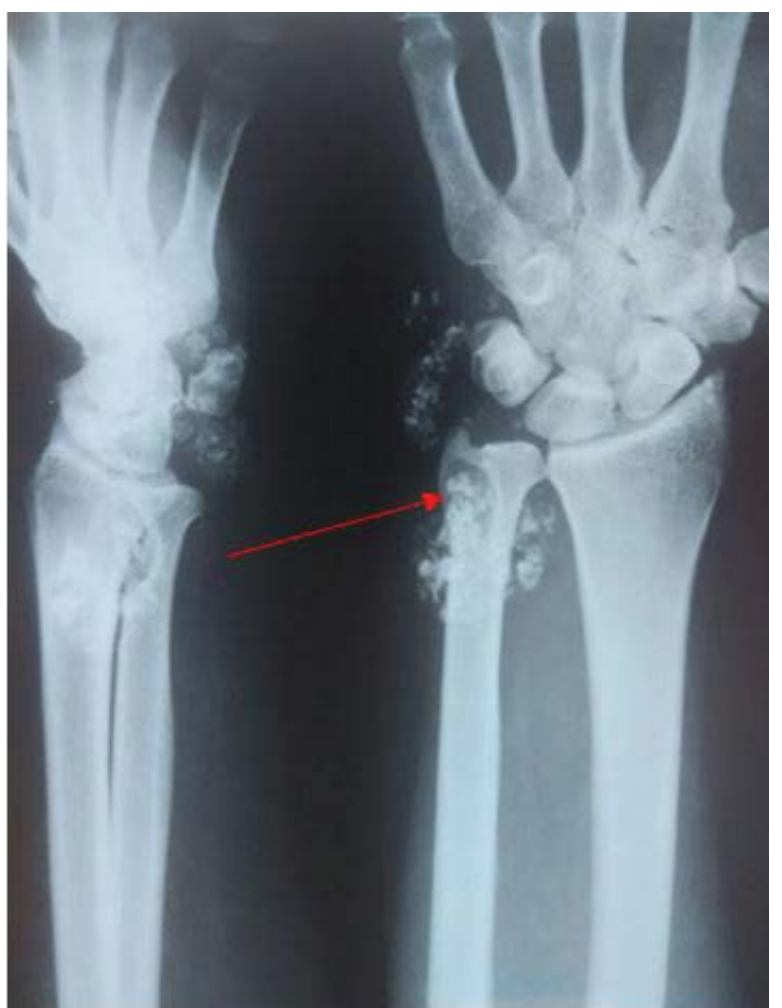

Figure 1: $P A$ and lateral $X$-rays of the right forearm and wrist showing calcified nodules consistent with synovial chondromatosis. Superficial cortical scalloping of the distal ulna is noted (apple core appearance).

nuclei and abundant indistinct cytoplasm. Occasional clusters show pronounced cytologic atypia. However, mitotic activity/necrosis is not noted in any of the smears. Cytological features favour a primary cartilage containing reactive lesion.

\section{Synovial chondromatosis}

A provisional diagnosis of Tumor calcinosis or chondrocalcinosis was rendered. Patient underwent complete synovectomy and loose body removal through a dorsoulnar approach and a separate incision over radial styloid under general anaesthesia and the tissue was sent for histopathological examination. The triangular fibrocartilage complex (TFCC) and the dorsal capsule of the distal radioulnar joint were preserved.

The distal aspect of the right volar radioulnar, radiocarpal, radioulnar, intercarpal, and carpometacarpal joints capsule was excised through separate dorsal and volar approaches (with excision of multiple osteochondral masses). We found multiple osteochondral loose bodies within the fourth through sixth extensor compartments; the first through third compartments were not involved. Numerous loose bodies were also noted within the radiocarpal, ulnocarpal, distal radioulnar, intercarpal, and carpometacarpal joints. There were numerous loose bodies within the flexor tendon sheaths from the carpal tunnel to the proximal interphalangeal joints.

There were no intraoperative and early postoperative complications (Figure 2). The patient's postoperative recovery was uneventful and he regained a full and painless range of motion in about 2 months. There was no recurrence till last follow up (6 Month; Figure 3). The lytic lesion ultimately healed at 6 month.

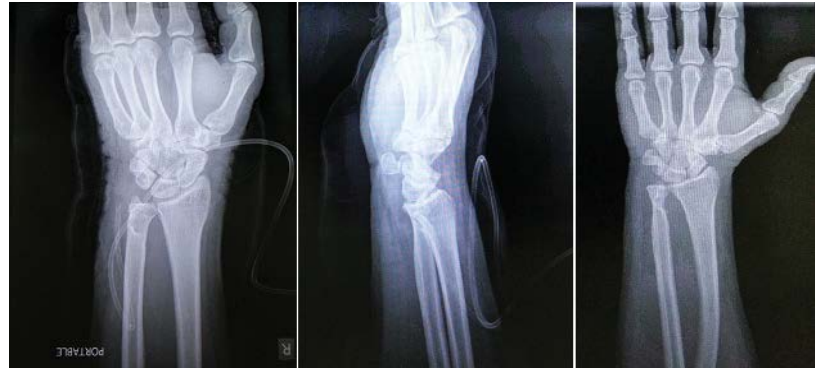

Figure 2: Post op x-ray right wrist PA and lateral views.

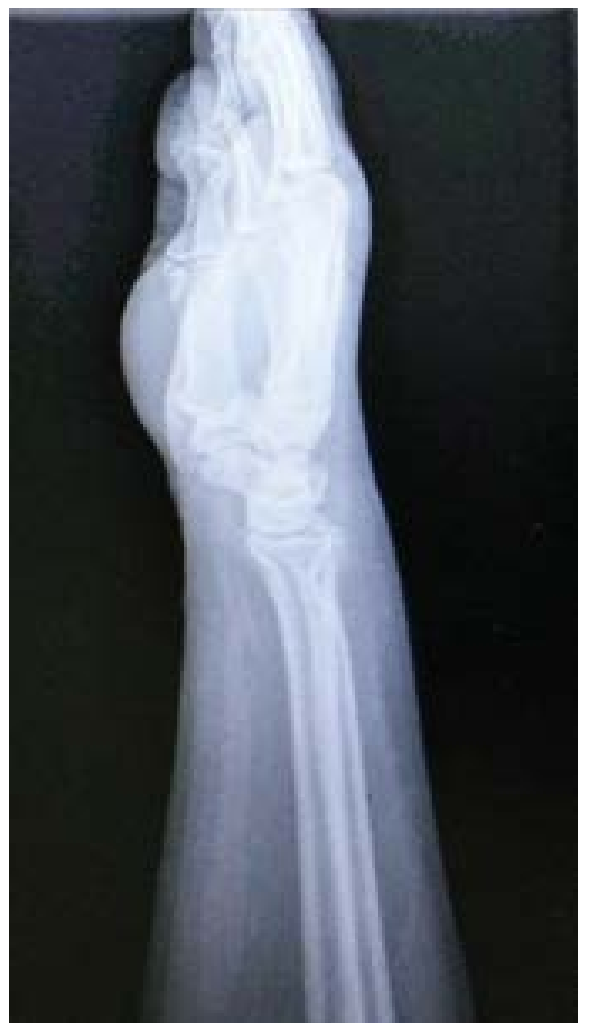

Figure 3: 6 month follow up x-ray right wrist PA and lateral views.

Grossly synovial membrane was covered with multiple grey white translucent polypoidal nodules of varying sizes (Figure 4). Cut section was gritty grey white in centre and translucent grey white at periphery. Histopathology of cartilaginous mass showed lobule of hyaline cartilage (Figure 5). Cellular atypia or mitosis is not seen. Few fragments of unremarkable synovial tissue are also seen (Figure 6). Histopathology confirmed the diagnosis of synovial chondromatosis.

\section{Conclusion}

The present case highlights the fact that synovial chondromatosis is a rare disease, especially in the wrist. Due to the fact that no calcification or ossification of the cartilage occurs in roughly one-third of cases, making a radiographical diagnosis of synovial chondromatosis is difficult. The diagnosis may be difficult when radiographs are normal and a CTscan is useful for detecting non-calcified loose bodies. There is still 
Citation: Kumar N, Mukhopadhaya J, Anand O (2016) Synovial Chondromatosis of Distal Radioulna Joint with Features of Lytic Lesion in a 29 years Male: A Case Report and Review of Literature. J Sports Med Doping Stud 6: 174. doi:10.4172/2161-0673.1000174

Page 3 of 3

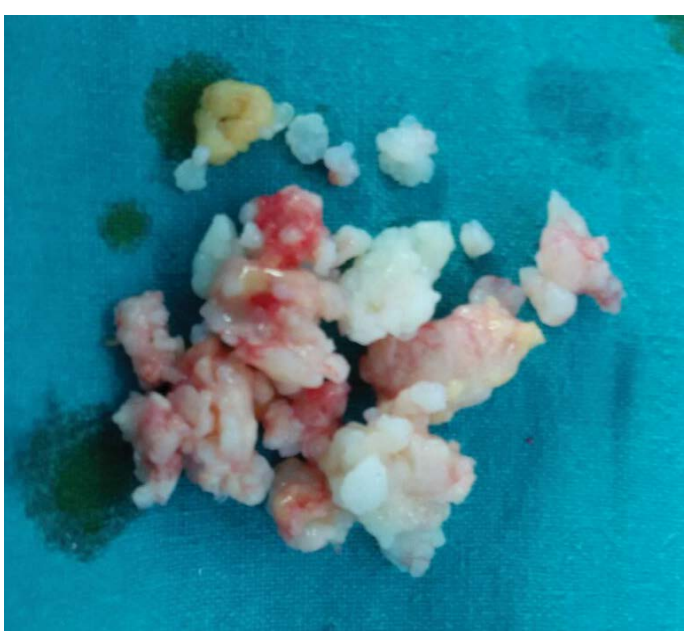

Figure 4: Removed multiple nodules.

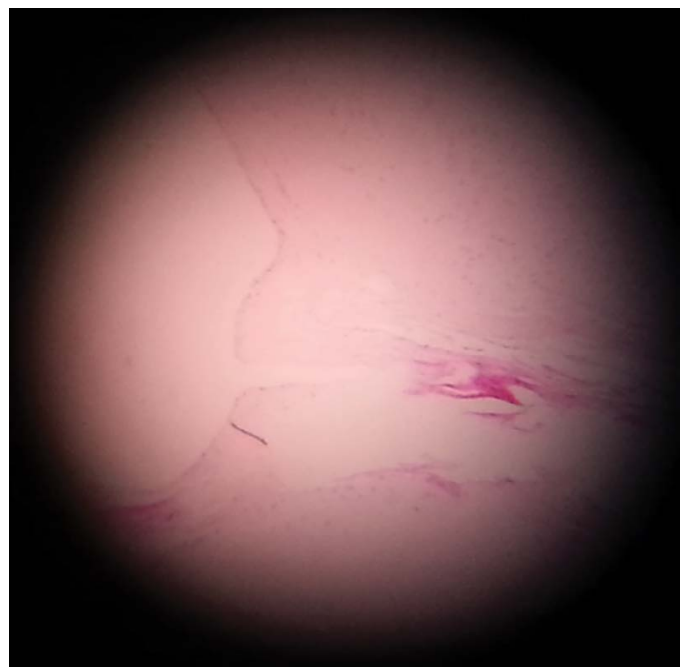

Figure 5: 4x magnification showing two lobules of hyaline cartilage meeting each other.

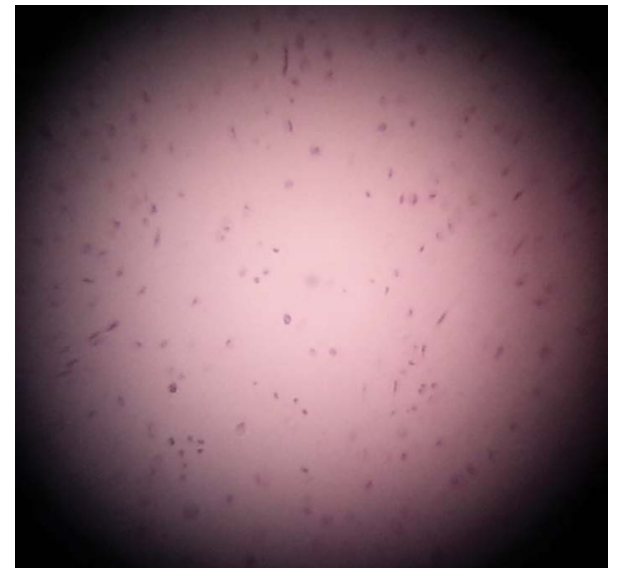

Figure 6: $10 \times$ magnification shows cartilage tissue without atypia discussion on whether synovial chondromatosis is a neoplastic process or a reactive metaplasia. It can be mistaken for malignancy and hence a combined clinical, radiological and histopathological approach helps in accurate diagnosis. There is no substantial risk for local recurrence but long term follow- up is necessary to gain more insight in the behaviour of this rare condition.

\section{References}

1. Coles MJ, Tara HH Jr (1997) Synovial chondromatosis: a case study and brief review. J Orthop (Belle Mead NJ) 26: 37-40.

2. Ono H, Yajima H, Fukui A, Tamai S (1994) Locking wrist with synovial chondromatosis: report of two cases. J Hand Surg Am 19: 797-799.

3. Oursin C, Wetzel S (1996) [Synovial chondromatosis of the hand]. Rofo 165: 421423.

4. Fetsch JF, Vinh TN, Remotti F et al. (2003) Tenosynovial (extraarticular) chondromatosis : an analysis of 37 cases of an underrecognized clinicopathologic entity with a strong predilection for the hands and feet and a high local recurrence rate. Am J Surg Pathol 27: 1260-1268.

5. Wu CW, Chen YK, Lin LM, Huang E (2004) Primary synovial chondromatosis of the temporomandibular joint. J Otolaryngol 33: 114-119.

6. Guijarro-Martínez R, Puche Torres M, Marqués Mateo M, Ignacio Solís G, Luis Miragall A, et al. (2002) Bilateral synovial chondromatosis of the temporomandibular joint. Journal of craniomaxillofacial surgery 39: 261-265.

7. Shearer $\mathrm{H}$, Stern $\mathrm{P}$, Brubacher A, Pringle T (2007)A case report of bilateral synovial chondromatosis of the ankle. Chiropr Osteopat 15: 18.

8. GeethalakshmiU,Amita K, Vijay S. Primary Bilateral Synovial Osteochondromatosis of the Knee Joint: case report. IJHSR 2: 87-91. 